\title{
APRENDER POR INTERMÉDIO DE DISCURSOS E IMAGENS CORPORAIS: TENSÕES CONTEMPORÂNEAS
}

Viviane Castro Camozzato

RESUMO: O artigo analisa, num primeiro movimento, práticas de controle e cuidado corporal. Num segundo movimento, foca em escritas que narram os que não reverberam, em seus corpos, os discursos corporais normativos associados às práticas de controle e cuidados corporais. Em ambos movimentos sobressai o quanto se aprende por intermédio de discursos e imagens que dizem de nós e dos outros, demarcando os efeitos das pedagogias culturais para a produção do que somos. As discussões são realizadas em torno de escritas que circulam em espaços da internet.

Palavras-chave: Discurso; Imagens corporais; Pedagogias culturais

\section{LEARNING THROUGH SPEECHES AND CORPORAL IMAGES: CONTEMPORANEOUS TENSIONS}

\begin{abstract}
The article a analyzes, at a first motion, control practices and corporal care. At a second motion, focuses in which writings that narrate the ones that didn't reverberate in their bodies the normative corporal speeches associated to the control practices and corporal care. In both motions excels how much we learn through speeches and images that talk about us and others, demarcated the effects of the cultural pedagogies for the production of what we are. The discussions are done around writings that circulate at the internet spaces.
\end{abstract}

Keywords: Speech; Corporal images; Cultural pedagogies.

\footnotetext{
Licenciada em Pedagogia, mestre e doutora em Educação pela UFRGS. Professora adjunta da Universidade Estadual do Rio Grande do Sul (UERGS). Coordenadora do Grupo de Pesquisa Educação, Culturas e Pedagogias Contemporâneas (UERGS/CNPq) e pesquisadora do Núcleo de Estudos sobre Currículo, Cultura e Sociedade (NECCSO). Coordenadora de área do Pibid, no subprojeto de Pedagogia da UERGS Bagé.
} 
A intenção é problematizar alguns modos pelos quais os sujeitos aprendem a se relacionar consigo e com os outros a partir de aprendizagens que se dão por meio de discursos e imagens corporais. Tenho o pressuposto de que somos alvo de constantes tentativas de assujeitamentos a discursos que envolvem as normalizações corporais contemporâneas. Tratarei destas discussões evidenciando, num primeiro movimento, práticas bem concretas de controle e cuidado corporal, as quais são tanto incitadas no tempo presente através de uma miríade de artefatos e espaços, quanto são produtoras de formas pelas quais certos sujeitos voltam para si, produzindo-se através das verdades advindas daí.

Num segundo movimento, focarei a análise em escritas que narram os que não reverberam, em seus corpos, os discursos corporais normativos associados às práticas de controle e cuidados corporais. Escritas que nos mostram formas de olhar e diminuir os que, de certo modo, "destoam" dos discursos mais em voga no contemporâneo e que, por isso mesmo, são falados, narrados, descritos, avaliados, julgados através do que mostram de si mesmo por meio de suas imagens corporais. Em ambos movimentos sobressai o quanto se aprende por intermédio de discursos que dizem de nós e dos outros - produzindo, inclusive, as imagens corporais que colonizam a esfera pública e privada.

“O que estamos fazendo de nós mesmos?" é uma inquietação nietzschiana que percorre o decorrer desse estudo. Esta inquietação levou-me a construir uma problematização em que a tônica está em almejar compreender como está se dando, contemporaneamente, a produção de si e dos "outros" numa cultura tão marcada por discursos relacionados aos corpos.

Em outras palavras, parto da premissa de que a centralidade do culto ao corpo instaura modos específicos de as pessoas lidarem, cuidarem, adularem, venerarem e se relacionarem com os seus corpos. Uma condição que aumenta proporcionalmente, por sua vez, os sentimentos e as reações de ódio, desprezo, crueldade, humilhação e hostilidade àqueles que, através dos seus corpos, parecem demonstrar menores submetimentos aos investimentos de discursos normativos. Nesse sentido, creio ser possível delinear um "elo" entre os modos pelos quais cada sujeito se vê, se cuida, e, consequentemente, os modos pelos quais esses indivíduos vêem os "outros", os quais muitas vezes são narrados de modos depreciativos, visando a sua "diminuição" frente aos adeptos dos contemporâneos parâmetros de normalidade. Trata-se de colocar em foco a questão de que há, em suma, uma inseparabilidade entre as questões “o que estamos fazendo de nós mesmos?”, “o que estamos fazendo de nossos corpos?" e, ainda, “o que estamos fazendo com os 'outros'?". 
Para tratar dessas discussões analiso, neste artigo, escritas de sujeitos que tem circulado, nos últimos quinze anos ${ }^{2}$, em redes sociais, blogs e sites da internet. A escolha por tais espaços virtuais envolveu o fato de que esses são espaços em que os sujeitos expressam aspectos de seus pensamentos que não seriam tão fáceis de serem revelados numa conversa mais formal. Importante demarcar que compreendo que tais escritas são tornadas possíveis por intermédio de aprendizagens que ocorrem na esfera social como um todo, tendo pedagogias culturais específicas para a sua construção, disseminação e perpetuação.

\section{Aprender as recorrências de um tempo preciso (uma ênfase na visibilidade e valorização de imagens corporais normativas nas relações consigo)}

Compreendo que as práticas que os sujeitos colocam em movimentação são fruto de aprendizagens sobre como cuidar e controlar a si, ao seu corpo, em consonância com os discursos a que estes mesmos sujeitos se filiam. Nesse sentido, é importante demarcar que por aprendizagem compreendo o processo que nos faz ou incorporar algo que nos era externo, ou repensar/reacomodar algo interno. Mas sobretudo, algo que envolve realocar entendimentos e concepções, implementando - ainda que por algumas vezes possam ser consideradas mínimas - alterações nos nossos modos de perceber a vida e seus processos, nós em relação aos demais, etc. Assim, se produzir a partir de discursos que envolvem, por exemplo, as normalizações do corpo na contemporaneidade, é algo que envolve processos de aprendizagem que ocorrem na cultura, por meio de práticas e técnicas que atravessam diferentes instituições e, sobretudo, pedagogias culturais espalhadas em pontos diferentes da nossa sociedade, nos ensinando como viver nesse tempo preciso.

Aprender é dotar a si mesmo de algo que provoca certa modificação nas formas de ser. Tem relação com uma operação que implica produzir a si mesmo a partir de determinados discursos que dizem, no caso deste artigo, sobre nós e nossos corpos. Como a esclarecedora argumentação de Gros (2004, p.620) evidencia: “o sujeito se autoconstitui

\footnotetext{
${ }^{2}$ Ao longo deste período tenho estado atenta a alguns dos - muitos - escritos de ódio que tem circulado na internet. Isso vem desde a minha pesquisa de mestrado (extraído para proteger o anonimato), o que justifica a variação das datas dos escritos. Importante registrar, nesse sentido, que as condições de produção do ódio continuam postas em nossa sociedade. O que, justamente, não faz desaparecer o tipo de escrita que aqui ficará visível. Contudo, é possível dizer que as reações críticas a essas mesmas escritas, a inibição ao anonimato na web, bem como as discussões sobre diferenças, politicamente correto, multiculturalismo, etc., que tem permeado a teorização social e educacional tem restringido um pouco, nos últimos anos, as condições de escrever de forma odiosa sobre os "outros".
} 
ajudando-se com técnicas de si, no lugar de ser constituído por técnicas de dominação (Poder) ou técnicas discursivas (Saber)." Logo, ao invés de apregoarmos as mazelas dos discursos corporais para nos situar e enquadrar, cabe destacar que isso é uma via de mão dupla: somos convocados a ocupar determinadas posições-de-sujeito nos discursos a que nos inscrevemos e, do mesmo modo, a ocupação dessas posições se efetiva quando atuamos sobre nós, quando colocamos em operação técnicas e práticas para a nossa produção.

Essas técnicas são vitais quando se trata de aprender: desde as aprendizagens na escola às aprendizagens mais diversas na ampla esfera social e pública - evidenciando a produtividade das pedagogias culturais, portanto -, pois parece ser necessário que elas se façam presentes quando se trata de produzir a si mesmo. Nessa direção, cabe salientar que os sujeitos não são simplesmente produzidos pelas objetivações, mas produzem-se, operando e voltando sobre si próprios, como ocorre, por exemplo, nas técnicas e práticas que se utilizam para fazer os seus corpos de determinado modo.

No artigo Da ascese à bio-ascese ou do corpo submetido à submissão ao corpo, Ortega (2002) faz uma diferenciação entre as práticas de bio-ascese contemporâneas, compreendidas como práticas que visam o assujeitamento e o disciplinamento, das práticas ascéticas da Antigüidade, que eram práticas de liberdade, uma vez que tinham relação com o objetivo de alcançar uma elevação espiritual maior e para isso, daí sim, fazia uso de um conjunto de exercícios tendo essa elevação como objetivo desejado (FOUCAULT, 2004). Isso nos mostra que as práticas recebem objetivos que não são os mesmos, e por isso podem produzir processos de subjetivação distintos. Ao contrário da ascese da Antiguidade - que tinha como objetivo central a constituição de sujeitos éticos e singulares -, as práticas discorridas por Ortega (2002) atendem ao apelo contemporâneo de um desejo de uniformização e adequação, com a premissa da perfeição corporal como algo de máxima importância para a existência.

Contudo, qualquer prática precisa ser analisada a partir das condições discursivas que as tornam possíveis. Assim, se a sociedade contemporânea está assolada por sociabilidades marcadas pela ideia de que "Força, rigidez, juventude, longevidade, saúde, beleza são os novos critérios que avaliam o valor da pessoa e condicionam suas ações" (ORTEGA, 2002, p.157), tais ensinamentos vão fazer parte de um conjunto de processos que, em diferentes pontos de intersecção de produção de sujeitos, eles vão balizar o conjunto de aprendizagens direcionadas a nós. 
Considerando o exposto, quero evidenciar o quanto, ao tratarmos de pedagogias culturais, estamos lidando com objetivações e subjetivações na cultura. Neste artigo, ao invés de tratar de objetivações - o que incluiria, por exemplo, analisar representações de corpo em algum artefato cultural, ou no interior de práticas institucionais escolares, entre tantas outras opções -, pretendo pensar o quanto as objetivações sobre o corpo no interior da nossa sociedade - o que chamo aqui de discursos e imagens corporais - tem produzido efeitos nas nossas subjetividades, tornando possível que escritas sobre o seu próprio corpo e o corpo dos demais sejam alvo de (re)avaliações intensas. Isso porque somos frutos da cultura e, portanto, de pedagogias culturais que nos ensinam o que valorar ou não, como proceder ou não, como olhar para si e para os demais, etc. Não se trata de imposição, como espero que fique claro, mas de jogos de saber-poder que vão ganhando força nas disputas pelos significados.

Além disso, quando tratamos de pedagogias culturais podemos, ao mesmo tempo, analisar aprendizagens específicas sobre este tempo preciso. Desse modo, as escritas analisadas neste artigo, por meio das práticas que se avolumam, nos mostram determinadas operações sobre si mesmo em consonância de certas relações com o saber e com o poder. É assim que nas escritas aparece, por exemplo, o manejamento de práticas bem diárias de controle e cuidado corporal - expressas, aqui, através de práticas que visam ao emagrecimento em prol do enquadramento às rígidas normas corporais, na maioria das vezes.

As práticas de cuidado e controle corporal a que me refiro são, de fato, práticas bem concretas e, algumas, contemporâneas, tais como: dietas alimentares - com controle na ingestão de calorias; pesagens constantes; atividades e exercícios físicos; cálculos de $\mathrm{IMC}^{3}$; definição de metas corporais a serem atingidas - especialmente através de um "ideal" de corpo advindo de alguma personalidade famosa; relatos escritos dos dias, rememorando-os; bem como as comparações estabelecidas consigo - por exemplo, através das fotos do antes e do depois, entre outras. Tais práticas aparecem nos ciberespaços analisados neste estudo através das escritas confessionais, uma vez que tais práticas parecem ser ressignificadas quando transpostas para a web.

Desse modo, é fecundo pensar os ciberespaços analisados aqui como dispositivos pedagógicos. Ou seja, "Qualquer lugar no qual se aprendem ou se modificam as relações que o sujeito estabelece consigo mesmo" (LARROSA, 1994, p. 57). WhatsApp, blogs,

\footnotetext{
${ }^{3}$ Índice de massa corporal (IMC) é uma medida internacional utilizada para o cálculo da obesidade. 
Instagram, Twitter, email, sites diversos, jogos eletrônicos, Facebook, atualmente, assim como o antigo orkut, entre outros, podem ser consideradas como contendo práticas pedagógicas "sempre que esteja[m] orientado[s] à constituição ou à transformação da maneira pela qual as pessoas se descrevem, se narram, se julgam ou se controlam a si mesmas." (LARROSA, 1994, p.57). Ao tratar de práticas de cuidado e controle corporal, portanto, estou evidenciando práticas pedagógicas que medeiam e ao mesmo tempo constroem formas específicas de se relacionar consigo mesmo e com os demais. E isso por intermédio das dimensões dos dispositivos pedagógicos expostas por Larrosa (1994): verse, expressar-se, narrar-se, julgar-se e dominar-se.

Nos ciberespaços analisados os sujeitos narram suas histórias sobre o que acreditam ser motivo de estarem "gordas", o que as está motivando a buscar modificar os seus corpos e as formas de verem a si mesmas, as práticas cotidianas que passam a assumir (ou mesmo intencionar) para realizar seus objetivos. Uma estratégia importante que identificada nos grupos de blogs é, precisamente, visitar outros blogs e lá deixar recados para que as pessoas visitem os seus endereços também. Assim a rede vai sendo armada, com conversas e escritas fluindo. Como segue:

Meu nome é Sara, tenho 25 anos e estou, atualmente, obesa. Meu peso atual é 93,05. Apesar disso venho melhorando a minha alimentação há algum tempo e emagreci no total 5 kilos. Resolvi a partir de agora, como uma força a mais, divulgar aqui, diariamente, como é a rotina do meu emagrecimento. Vou scannear sempre que puder o resultado da balança. O Blog está programado para ter início no dia 07/04/2003. Ainda estou dando os retoques finais no layout e coisas desse tipo! Vou inclusive mostrar minha fotos do meu antes e meu depois. Eu tenho certeza absoluta que vou conseguir. Cansei escutar a frase: - Nossa! Você é tão bonita de rosto, porque não emagrece? (Grifos meus)

O post ${ }^{5}$ destacado acima, o primeiro do blog Meu emagrecimento, mantido pela blogueira Sara, refere-se ao fato de que uma das principais motivações para as escritas é que as redes criadas sejam um incentivo para enfrentar as dificuldades de manter uma dieta. Além disso, talvez caiba destacar o próprio papel da escrita na efetivação de um distanciamento necessário para poder olhar para si de um modo diferente e, com isso, também poder operar um retorno a si, onde aquele sujeito que éramos no momento da escrita já se esvaiu com a passagem do tempo. Tempo que, aliás, nos distancia do que

\footnotetext{
${ }^{4}$ As escritas extraídas da internet não foram revisadas. A opção é por manter as marcas próprias de escrita de cada sujeito.

5 Se muitos blogs se assemelham a diários virtuais, post (ou a ação de postar) se refere às cartas, às correspondências, enfim, os escritos disponibilizados nesses espaços.
} 
supomos ter sido um dia, pois a subjetividade, enquanto produção, constantemente é ativada a fazer-se outra. A ressignificação de si, a meu ver, pode ser realizada a partir de um retorno a si mesmo, efetivado por meio dessas escritas. Essa é uma prática que Schittine (2004) salienta, pois, a maioria dos blogueiros costuma fazer esse retorno ao relerem os seus escritos constantemente. Afinal, algo pode acontecer nesse encontro entre o passado e o presente e, com isso, gerar outras coisas.

Através da escrita, como exercício de si sobre si, cada um assimila "a própria coisa na qual se pensa. Nós a ajudamos a implantar-se na alma, a implantar-se no corpo, a tornar-se como que uma espécie de hábito, ou em todo caso de virtualidade física" (FOUCAULT, 2004, p.432). Essa escrita, no qual nos inscrevemos no curso de nossas vidas, marca a nossa alma e corpo. Nesse sentido, cabe salientar o papel da técnica utilizada pelas blogueiras - vestígio da sua forma de diário virtual - de escrever como foram os seus dias, relatando o que e de que modo comeram, se praticaram exercícios, como isso ocorreu, o que compraram, o que as estimularam, quais "deslizes" nas dietas foram cometidos, e assim por diante. Um modo de apreender para si certos discursos verdadeiros que elas querem ter marcados em si mesmas, talvez para se constituírem com uma armadura para poderem deixar de ceder às tentações altamente calóricas que podem assolá-las. Como salienta Ortega (2002), as práticas de bioascese utilizam-se de técnicas que eram utilizadas na ascese da antiguidade, mas os seus objetivos é que variam, ou seja, a ligação dos sujeitos a certos significados valorizados em nossa época que são inquestionavelmente diferenciados.

Assim, parece que, quanto mais desvios ou faltas cometidas são expressas tanto nos blogs quanto nas redes sociais, menores serão as possibilidades de neles incorrer. Essa pode ser uma técnica de si corriqueira em nossos dias, propriamente esse ato de narrar o seu dia através da alimentação, técnica essa que já víamos nos gregos, mas com formas e significados distintos, obviamente. Cabe destacar, ainda, o quanto a confissão é evidentemente marcada nos blogs - aparecendo em alguns momentos também em grupos das redes sociais -, enquanto espaços propiciadores dos sujeitos poderem dizer a "verdade" de si para si e para os outros, sobretudo se examinando.

Longe de querer fazer um juízo de valor sobre a nossa época, interesso-me em problematizá-la para pensar nos fios de nossa própria constituição como sujeitos de verdades específicas que estamos sendo. Assim, nos atuais tempos, "já não é o corpo a base do cuidado de si; agora o eu só existe para cuidar do corpo, estando a seu serviço" (ORTEGA, 2002, p.167). As preocupações sobre o tornar-se-outro-de-si-mesmo parecem 
inclinar-se, atualmente, para tornar-se outro na aparência, já que pareço existir somente se admirada pelo olhar do outro - atitude que evidencia a submissão ao corpo, porque, ao que parece, dependemos dele para mostrar quem, o que e como somos.

As produções de si por meio da escrita atendem à necessidade de visibilizar-se no espaço público, estando dentro das práticas confessionais. Atendem à necessidade tanto de "fazer falar" quanto a de "ser visto". Entretanto, isso faz parte do processo de escrever e, ao mesmo tempo, de ser inscrito por aquilo que se escreve, pelo modo como se escreve e, ainda, nos espaços internáuticos em que há trocas de mensagens, ser inscrito pelos comentários de outros sobre o que escrevemos anteriormente. Nesse processo, nos produzimos enquanto sujeitos de discursos específicos.

Escrever de modo confessional contribui, ainda, para "estimular algum tipo de reflexão crítica que modifique a imagem que os participantes têm de si mesmos e de suas relações com o mundo, o que [. . .] se chama de "tomada de consciência'." (LARROSA, 1994, p.47). Em recorrentes momentos me deparei com escritas que alertam para a necessidade de "tomar consciência" sobre as condições corporais: o pior é a consciência pesada, qualquer coisa q como, me arrependo depois, e apelo pros laxantes!!!!!! Ou, ainda: preciso tomar conciencia da minha condição de gorda para poder modificar isso. Aiiii, é duro isso. Me ajudem!!!!!!!!!!!!!".

Assim: observar, narrar, avaliar, classificar, particularizar, medir, comparar, eis uma infinidade de estratégias criadas para ordenar e tornar produtivos os corpos. É assim que o corpo vem se tornando central para atestar as formas de ser que estamos assumindo nestes tempos, como um novo marcador social (DAMICO, 2004). Aprendemos, cotidianamente, a supor que existem "marcas" nos corpos que nos dizem, fielmente e quase sem engano, como são os sujeitos que estamos enquadrando. Tais "marcas" mostrariam as diferenças como efeitos da natureza, e não como um processo de fabricação cultural, social e histórico, datado e localizado dentre certos regimes discursivos que atribuem valores específicos aos diferentes modos de existência.

Através do corpo acreditamos que podemos mostrar como realmente somos, como se o "ser" de um modo não fosse a simples apreensão momentânea de um dos vários modos de ver uma existência que se esvai a cada instante. Cabe ressaltar, ainda, que as análises culturais contemporâneas vêm questionando, cada vez mais, a ideia de que o corpo é definido biologicamente, um "dado" adquirido com o nascimento. Mais do que um

\footnotetext{
${ }^{6}$ Excertos da comunidade No Food, no tópico Desabafo, da rede social orkut. 
cruzamento de genes e células, o corpo é fruto de uma construção cultural, histórica e social, e é assim que o corpo adquire as marcas da sua cultura, que é dotada de significação.

Nesse sentido, falar de corpo implica envolver os seguintes aspectos: a) falar da sua construção; b) seus cuidados, ou seja, os investimentos que cada sujeito faz sobre si mesmo de modo a preocupar-se consigo - o que evidência modos distintos de cuidado em nossa época e sociedade; c) embates entre liberdade-controle, pois vemos uma "liberdade" que envolve um processo concomitante de controle, enquanto processos que não se operacionalizam separados, mas em conjunto. Afinal, com a crescente responsabilização de cada indivíduo pelo seu sangue, pelas suas células, a liberdade parece estar em cuidar do seu corpo de modo a construí-lo como o sonhado. Todavia, essa sensação de liberdade traz consigo novos modos de controle - e de controlar-se.

Penso que essa discussão configura-se como importante, devido ao meu objetivo de situar as relações que mantemos conosco e com os "outros" no tempo e espaço. Afinal:

Se admitimos nossa radicalidade histórica, ou seja, que estamos inapelavelmente imersos em culturas cujos discursos e práticas nos instituem como sujeitos históricos que somos, interessa-nos procurar compreender os processos que nos constituem e nos quais nos constituímos. (COSTA, 2005, p.206-207).

Ora, se, como já me referi anteriormente, as relações que cada sujeito estabelece consigo relacionam-se com os modos de se relacionar com os "outros" - enquanto práticas produtivas -, não poderia falar das produções recorrentes dos "gordos" como "outros", sem articular essas discussões ao escopo da cultura, uma vez que "São os textos circulantes no império cultural que estão nos inventando e fazendo de nós o que somos" (COSTA, 2005, p.211). Trata-se, enfim, da necessidade de compreender as práticas no interior de formações discursivas que as tornam possíveis e, muitas vezes, até desejáveis.

\section{Aprender a olhar e diminuir os que nomeamos como "outros" (uma ênfase nas imagens corporais "destoantes")}

Existe um olhar que parte da mesmidade. Outro que se inicia no outro, na expressividade de seu rosto. Talvez esta distinção seja uma forma para poder olhar entre aquelas representações, aquelas imagens que tomam como ponto de partida e como ponto de chegada o eu mesmo, mesmo - sumidouro, o refúgio do próprio corpo e do mesmo olhar -, e aquelas que começam no outro e se submetem a seu mistério, seu distanciamento, sua rebeldia, sua expressividade, sua irredutibilidade. Uma imagem do mesmo que tudo alcança, captura, nomeia e torna 
próprio; outra imagem que retorna e nos interroga, nos comove, nos desnuda, nos deixa sem nomes. (SKLIAR, 2003, p.67-68)

Conforme as colocações de Skliar, há dois modos de olhar para o outro. Um modo que busca, ao olhar o outro, encontrar um pouco de si, o seu reflexo, o que torna possível que, ao não encontrar um simples reflexo, busque nomear, marcar, diferenciar, capturar esse outro. Outro modo que se abre aos mistérios do outro, à sua irredutibilidade, ao que o outro nos produz ao nos interrogar, nos colocar em suspensão. Trata-se de modos distintos de olhar: um parte da mesmidade e o outro da alteridade. Diferenças "entre um olhar que identifica, classifica e ordena, que pretende determinar o quê de cada coisa e que se há de fazer com ela, e um olhar que vive, que se move, que se cruza com outros olhares, com outros corpos". (LARROSA, 2004, p.271). Levando isso em consideração, adianto que, nesta seção do artigo, trago modos de olhar para os "outros-gordos" que estão localizados na mesmidade e que, além disso, visam a uma diminuição desses sujeitos.

Importante salientar, nesse sentido, que a "diferença" não é algo que esteja apenas no corpo, visto que é produzida no interior das relações que mantemos com os sujeitos. Trago, em relação a isso, alguns excertos sobre alguns dos modos pelos quais as modalidades humanas caracterizadas como "gordas" são nomeadas. A seguir, o excerto extraído da comunidade do orkut Eu odeio gordas que se acham, dentro do tópico Você tem alguma história engraçada de gorda?:

Pathy Essa historia nem eh engraçada, mas eh mto.... Irritante Pessoal... eu fui num show ontem (20/11)e por azar, fiquei rodeada de gordas/os... a primeira cena foi engraçada.. olho pra pista... vem uma gorda gigantesca com um cabelo mal pintado de loiro... uma blusa rosa com uma florzinha de pano rosa pink na blusa... uma saia mto curta marron e um sapatinho \{ou tenis, sei lah\} rosa tbm.. ahhahaha.. ela correndo pareceu uma vaca feliz no campo!! Depois começou as cenas irritantes: Uma gorda na minha frente cum um cabelo cumpridu e nojentu solto (num show de rock??!!) e falandu altu e si achandu td... falandu altas mintiras prum cara q tbm era gordu q tava nu ladu dela.. nossa.. ela si achava mtooooooo... du meu ladu uma outra gorda loira falsa, mais tiazona jah... cum uma roupa mto piniquenta (como eu sei? qdu começou o show ela qs mi derrubou cum akelis braços gordos e suadus ... na primeira music jah tava td nojenta.. iéca!) e du ladu meu outru ladu.. um gordu nojentu tbm.. na primeira music jah tava fedendu e suadaum (esse tbm si achava mto!!).. mi impurrou um monti ateh fica na minha frenti.. tbm bati mto nas costas nojentas dele.. ahuahuah.. depois resolvi ir mais pra tras.. pq akele ambiente tava mto inospito.. ahuahuahuhauhauah.. eh issu aí galera.. apesar da pessima experiencia cum gordos/as nojentos/as e q se acham mtuuuuu o show foi mto bom.

O que vemos é a marcação sobre quem é o "diferente", "estranho", a "aberração", o ser "bizarro" - conforme nomeações que são referidas às mulheres consideradas 
"gordas" em alguns espaços virtuais -, enquanto estratégia de fabricação, localização e diminuição desse "outro". Para receber o selo de "outro", esse ser precisa surpreender, perturbar, inquietar frente ao status quo, pois se o Mesmo se vê refletido nele, ele não é o "outro", e sim um igual à referência. As estratégias narrativas sobre "quem são" os "outros" servem como garantia para a construção de significados sobre as diferenças que, por serem produzidas na linguagem, "necessitam" de um espaço de visibilidade para serem faladas e indagadas em sua própria diferença.

No caso das escritas anteriores, podemos indagar: quem está falando? Uma pessoa que se situa - e é situada - dentro dos atuais padrões corporais para falar de si ao estar falando do/e pelo "outro", que não tem como falar de si próprio. Nessa situação específica, provavelmente por estar confortável na sua posição de "normal", a narradora da história encontra-se autorizada a definir o "diferente" através do controle dos significados sobre esses sujeitos. Enfim, o "outro" é falado, narrado e produzido como fora do padrão e, desse modo, pessoas como a citada se constroem e se reafirmam como indivíduos "normais". Uma busca, em suma, de construir pertencimentos e exclusões através da criação de fronteiras entre os tidos "normais" e os "anormais".

Sobre os sujeitos que se autorizam a falar sobre/e pelos "outros", cabe ressaltar que normalmente esses sujeitos que escreviam nas comunidades Eu odeio gordas e Eu odeio gordas que se acham, do orkut, por exemplo, eram mulheres e homens que se narravam como adeptos da malhação, que gostavam de "baladas", de paquerar, de serem vistos e admirados. Ou seja, sujeitos que estão "dentro" dos padrões de normalidade contemporâneos; pessoas que se julgam "dignas" de definir quem são os "outros", já que eles se vêem como homens e mulheres "normais": Graças a Deus eu sou LINDA, MAGRINHA , SUPER D BEM COM O ESPELHO!!!! E não preciso provar nada pra GORDA nenhuma!!!!'. Com isso, “algumas [identidades] gozam de privilégios, legitimidade, autoridade; outras são representadas como desviantes, ilegítimas, alternativas. Enfim, algumas identidades são tão 'normais' que não precisam dizer de si; enquanto outras se tornam 'marcadas' e, geralmente, não podem falar por si" (LOURO, 2000, p.67, grifos da autora). Além do mais, o que parece estar sendo construído, dia a dia, é um cuidado de si através do controle do "outro", ou seja, se narra os outros para que cada um construa a si próprio e se reafirme dentro de certos parâmetros que são os construídos como "desejáveis".

\footnotetext{
${ }^{7}$ Excerto da comunidade Eu odeio gordas que se acham, no tópico E então gordas?, escrito pela orkuteira PsYLocKe.
} 
Desde a pesquisa inicial (defendida em 2007), continuo analisando o panorama de produção das imagens e discursos corporais, tentando ver possíveis transformações nos modos de olhar para si e os demais a partir disso. Algo que é notável, nesse sentido, é que ao contrário do espaço-tempo do orkut, em que o anonimato, muitas vezes, fortalecia a expressão do preconceito e da discriminação, agora se vê uma menor aceitação do anonimato, dos perfis fake, o que tem minimizado, no Facebook, escritas tão diretas como as anteriores. Mas ao mesmo tempo, isso não significa que os modos de olhar para os corpos das pessoas nomeadas como "gordas" tenham se alterado, ou mesmo que tenhamos, enquanto sociedade, abdicado das funções avaliativas e julgadoras em relação a esses mesmos corpos-imagens.

Nessa direção, as escritas recentes da rede social Facebook, parecem evidenciar uma diminuição na quantidade de postagens - agora mais marcadamente quase que redigidas em forma de "manchetes":

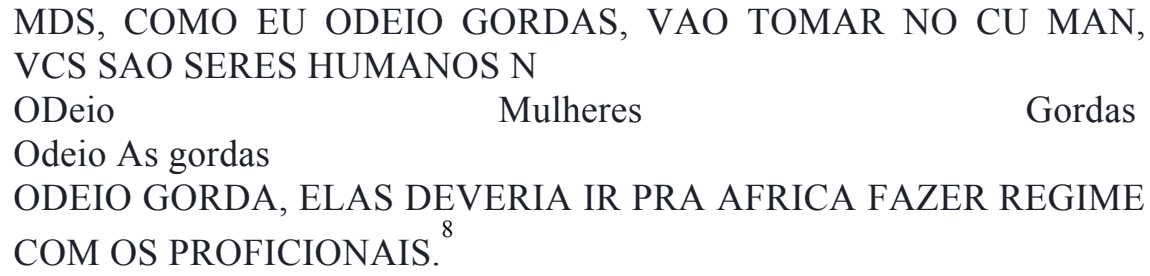

Como já referido, é aparente, desde o período inicial da pesquisa, como comumente sabemos, que o anonimato favorece a circulação de escritas odiosas. Uma amostra disso a seguir podemos ver no site "Eu Confesso", por um perfil intitulado Magra:

Eu confesso que odeio gordas. Qual eh dessas obesas? Ficam exibindo suas panças nojentas como se fosse bonito. Ficam colocando decote para que vejamos aquelas coisas pulando pra fora da blusa! Dá vontade de vomitar. Pq uma mulher teria orgulho de ser obesa? E nada dessa de "gordinha". "gordinha eh aquela que consegue disfarçar a barriga com uma blusa larguinha, que tem 2 ou $3 \mathrm{kgs}$ a mais, não aquele mastodonte, aquela baleia com 20, $30 \mathrm{kgs}$ a mais. Isso eh obesidade! Isso eh repugnante! Isso eh nojento! Eu tenho pena dos otários que casam com essas bolhas monstruosas. Já pensou, um sujeito normal tentando ir pra cama com aquela coisa gelatinosa, redonda? E quando resolvem parir? ARG! Não tem como parir. Mesmo abirndo espacato ainda ficam bolas e bolas de gordura que impedem o bebê de sair. E coitado do médico que tiver que fazer a cesária desse mostro horrorosso! Essa raça tem que ser eliminada, extinta. Põe essa raça num campo de concentração, pq eh o que as obesas merecem! 9

\footnotetext{
${ }^{8}$ As escritas desse parágrafo estão publicadas no modo público do Facebook.

${ }^{9}$ Escrita disponível em http://www.euconfesso.com/confissao-118008.html
} 
Expressões como "odeio", "panças nojentas", "repugnante”, "baleia", "mastodonte", "bolhas monstruosas", "coisa gelatinosa", "monstro horroroso", demonstram o quanto as palavras expressam as marcas do preconceito e da discriminação, e por isso são eficazes quando se trata de nomear, avaliar e julgar os sujeitos socialmente construídos como “outros". Ao mesmo tendo, evidenciam a estratégia de autoafirmação identitária realizada em processos desse tipo. Isso porque, como já comentando anteriormente, muitos que se colocam nessa posição de sujeitos que confessam o ódio sobre determinados tipos de sujeito se reafirmam como "normais", como a norma: Já pensou, um sujeito normal..., como a Magra escreveu. A finalização da postagem - Essa raça tem que ser eliminada, extinta. Põe essa raça num campo de concentração, pq eh o que as obesas merecem - indica, ainda, o quanto se trata de decidir sobre quem vive e quem morre, o que evidencia a permanência com que seguem incrustadas em nossa sociedade práticas que intentam matar a alteridade. Trata-se, em suma, de um tipo de permanência discursiva que não temos sido capazes de extinguir - e provavelmente nunca seja possível, embora tenhamos a expectativa de um esmaecimento disso.

Importante salientar que as escritas sobre os "outros" não são produções "individuais", pois tiveram condições de possibilidade para emergir numa cultura em que há o silenciamento e a negação de modos outros de ser e perceber o mundo. Podemos pensar, assim, em todas as discursividades que produziram os enunciadores dos excertos expostos anteriormente, possibilitando que expressassem os seus desprezos pelas pessoas "gordas". Afinal, estamos inseridos numa cultura em que esse tipo de enunciado é construído, legitimado, disseminado, tornando-se um regime de verdade.

Além disso, como afirma Silveira (2002): “Os textos são produzidos a partir de discursos e de linguagens [...] que não apenas (e não principalmente) 'expressam' e 'comunicam' - como as análises clássicas das funções da linguagem nos ensinavam - mas também 'constroem' e 'constituem' a realidade” (p.19). Com isso, quero reiterar que as escritas tornadas públicas trazidas neste artigo - e que demonstram ódio às pessoas nomeadas como "gordas", entre outros tipos que poderia elencar - não são a simples expressão da "verdade" dos comunicantes ou dos alvos da comunicação, mas artifícios produtivos para a fabricação dos significados e imagens criadas sobre os sujeitos nomeados como "outros" incluindo, ainda, as imagens que esses "outros" têm de si.

Como salienta Moita Lopes (2001), através das práticas narrativas os sujeitos são construídos, assim como constroem os outros e se ligam ao mundo social. Desse modo, as práticas narrativas podem ser vistas como ações devido ao que produzem, e analisá-las nos 
possibilita ter "acesso à socioconstrução das identidades sociais" (Moita Lopes, 2001, p.63). Os efeitos das histórias que contamos e que nos são contadas - neste caso, histórias escritas - podem ser visualizados no excerto destacado a seguir, em que a autora demonstra o seu sentimento em reação a piadas e gozações - construídas nas contingências macrossociais que nos atravessam, e que, de fato, atravessaram membros do seu meio familiar $^{10}$ :

Ando meio magoada com as pessoas em especial as da minha família domingo fiz um almoço pro meu pai, Depois de mais de 1 ano sem nos vemos. Tudo poderia ter saído bem, mas não foi assim. poxa quando você fica muito tempo sem ver alguém, não espera que a primeira coisa que ela fale e o quanto você esta gorda e coisas do tipo Brincadeiras sem graça que consegue derrubar e humilhar qualquer um. Bom foi isso que aconteceu Eu estava tão ansiosa por esse almoço. Mas meu pai fez questão de estragar ao chegar falando mal da comida, colocando defeito em tudo. Mesmo sabendo que eu não cozinho tão bem Ha não ser doces, isso infelizmente eu sei fazer. Na verdade na hora que ele chegou ao invés De falar "oi", foi logo falando: "nossa você esta bem mais gorda hein?". Ate então tudo bem, mas piadas do tipo. Deixa-me subir primeiro na escada porque vai que vc entala Ou do tipo "nossa se você virar muito na cama é capaz de esmagar alguém". Me detonou, o pior foi ouvir esse tipo de coisa do meu pai. E na frente de todos que estavam aqui, eu me senti humilhada. Detonada.Claro que sei que estou gorda, sei que tenho que emagrecer. Mas mesmo assim isso não e motivo pra ninguém usar como piada to ate hoje meio pasma e chateada.

E mesmo a declaração de Érika, a seguir, que nos relata como engordou e, posteriormente, o que a motivou a buscar o emagrecimento. Inclui-se, no desfecho, a contribuição do seu blog e da sua rede de amizade construída nesse espaço:

Meu nome é Érika, tenho 31 anos, sou casada, mãe de lindo garotinho chamado Eduardo. Moro na cidade de Mogi das Cruzes-SP e como muitas outras pessoas estou lutando para tentar emagrecer. Vou contar um pouco de como tudo começou. No ano de 1997 cheguei a pesar 120 quilos, resultado de um acidente que sofri no Japão em 1996. Quando retornei ao Brasil, todos ficaram muuito espantados, e com toda a certeza, pois antes de embarcar para o Japão eu pesava 65 quilos. Determinada a emagrecer fiz todo tipo de tratamento médico, desde a ingestão de medicamentos a dietas malucas. Do ano de 1997 até o ano 1999, emagreci 23 quilos, chegando aos 97 quilos e mantive este peso até o ano de 2001. Em outubro de 2001 engravidei e no final da gestação, após o nascimento do meu filho, estava pesando 116 quilos. Não tive maiores problemas para perder os quilos adquiridos na gestação, porém em janeiro deste ano, fomos ao Parque Aquático Wen't Wide, ao lado do Hopi Hari, e lá passei por uma situação muuito constrangedora, que não tive coragem de contar para ninguém até hoje. Estava com meu filho, para variar estava correndo atrás dele, quando passei na frente de um grupo de jovens e escutei um deles comentar: Nossa!!! Que horror!!! Que japonesa mais gorda? Ninguém merece ter

${ }^{10}$ Extraído do diário virtual Emagrecendo. 
uma visão dessas neste dia tão lindo!!! e todos começaram a rir. Para piorar a situação, eu tinha que passar na frente deles novamente, e escutei outro comentário: - Ah não, assim não dá! Será que ela não se toca. Gente.....me senti muuito mal, fiquei com vontade de chorar e passei o resto da tarde deitada na espreguiçadeira super deprimida. Até então,eu não tinha a noção do quanto estava obesa, e do quanto nós somos penalizados e massacrados por causa disso. O melhor de tudo é que, esse comentário maldoso mudou minha vida!!! Foi a gota d'água!!! Então comecei uma dieta com o auxílio de uma nutricionista e descobri que não existe nem uma mágica para emagrecer, o segredo é a reeducação alimentar combinada com atividade física diária para queima de calorias. Mas, tudo era muuito monótono... e para seguir o cardápio da dieta que ela havia me passado eu tinha que, ou ganhar muuito bem, ou ter maridão rico que bancasse tudo, e como não tinha nem uma coisa e nem outra, desisti. Mas não engordei, muito pelo contrário, até que perdi alguns quilos. Até que um dia, navegando pela internet descobri as blogueiras light através da Revista Dieta Já, e fiquei muuuito interessada. Como não entendia nada de Blog e de HTML, pedi uma ajudinha para um primo, o querido Rafael, que me ajudou a montá-lo. No começo tudo era muito tímido, tinha vergonha de postar, era desconfiada, até que recebi meu primeiro comentário e conquistei minha primeira amiga light a Camila, logo vieram mais e hoje já são muitas. O resultado de tudo isso? Você pode conferir logo abaixo, quando iniciei meu blog em 22/07/2005 ${ }^{11}$.

As notícias e informações que nos chegam através dos mais variados espaços contemporâneos gravitam, diversas vezes, em torno dos males da obesidade, assim como dos modos de cuidar do corpo e da saúde, incluindo ensinamentos sobre os procedimentos relacionados com lipoaspiração, cirurgia plástica, entre tantos outros. Como formas produtivas de construção de sujeitos e realidades, os ensinamentos urdidos nas tramas da cultura produzem. Produzem diferenças, (pre)conceitos, normas, padrões estéticos e comportamentais, singularidades, efeitos... Desse modo, creio que as histórias selecionadas apontam a reverberação desses discursos, pois eles confluem nos modos de subjetivação que incitam, os quais podemos ter "acesso" através das narrativas que expõe o "outro" e, por outro lado, através das que dão a palavra para que esse "outro" fale, diga a sua palavra e diga de si.

Creio que há de se pensar que "todos nós, como sujeitos discursivos, deveríamos ser sensíveis às dimensões que fazem da linguagem cotidiana um lugar privilegiado de consagração do preconceito, do desprezo, do repúdio, da ridicularização e, mesmo, do ódio" (SILVEIRA, 2002, p.22). Nesse sentido, as narrativas demonstram o quanto criamos e recriamos, a todo instante, "outros", enquanto nós, os Mesmos, nos auto afirmamos. Ora, enquanto criações, as diferenças não são dadas, naturais, ou mesmo estáticas, mas são

11 Extraído do blog Diário de emagrecimento. 
tornadas diferenças em relação a outras diferenças que, aliás, se dão nas tramas do cotidiano, através de discursos assumidos na forma de "verdades".

Saliento, inclusive, que os preconceitos - visíveis nas escritas expostas aqui - são direcionados a sujeitos que "destoam", por questões diversas, dos corpos-modelo que a sociedade contemporânea vem apregoando e fabricando. Nesse sentido, cabe salientar que procuro me distanciar de análises que, de modo um tanto ingênuo, vêem o ciberespaço como que apartado da sociedade em geral. Como exemplo, posso destacar o quanto tem sido veiculado na mídia - ou mesmo em estudos que problematizam o bullying e ciberbullying $^{12}$ - que essas práticas de discriminação podem ser isoladas, amarradas que estariam a um particularismo que nos impossibilita percebê-las como encarnadas nos próprios modos de nossa sociedade se constituir e de se fazer presente no contemporâneo. Ressalto, assim, que os modos de "relação consigo", bem como os modos de "relação com os "outros", gestados a partir de olhares preconceituosos que classificam e hierarquizam as diferentes existências, estão sendo sustentados pelo contexto social e cultural que os tornam possíveis, dando sustentação a tais práticas.

É assim que, talvez, o mais importante seja a necessidade de não se separar o que acontece na web das dinâmicas sociais e culturais, pois elas não são coisas apartadas, por mais que pensá-las como autônomas nos dê a tranquila sensação de que o nosso mundo não produz os posicionamentos, percepções e sentimentos presentes no ciberespaço, uma vez que são postas como práticas situadas localmente - como se estas práticas fossem algo isolado na nossa cultura -, que surge numa relação específica, não envolvendo as redes discursivas que as tornam possíveis. Afinal, as reações de repulsa aos sujeitos tidos como "possuidores" de corpos "outros" não são meras expressões de seus comunicantes, mas posicionamentos construídos no interior de uma cultura que cria saberes específicos para cada tipo de modalidade humana. Contribuindo, assim, para as classificações e hierarquizações que promovem a demarcação dos lugares sociais cabíveis aos diferentes sujeitos ou, mesmo, aos sujeitos tidos como "diferentes".

Frente a tudo isso, vale perguntar: "Conheceis essa sensação de diminuir dentro de alguém?” (GOMBROWICZ, 2001, apud LARROSA, 2004). Tal sensação manifesta-se a partir de modos de nomear e olhar os outros. De olhares que partem de cima,

\footnotetext{
12 O primeiro termo refere-se a atos de violência física e/ou psicológica praticados por um (ou mais) indivíduo sobre outro(s). Ciberbullying, por sua vez, refere-se a tais atos no ciberespaço, como chacotas, gozações, humilhações na web.
} 
verticalizados, que referendam a mesmidade. Trata-se "de que cada um de nós somos definidos e criados na alma dos demais, de que nós mesmos definimos e criamos aos outros com as imagens que formamos deles." (LARROSA, 2004, p.265). Trata-se, ainda, do quanto alguns indivíduos só sentem-se grandes diminuindo os outros, transformando-os em "outros" porque nomeados, olhados, escritos, ditos, inscritos como diferença a servir para o engradecimento do Mesmo. Movimento duplo: rebaixamento e auto-elevação. É que a outorgação da diferença e do Mesmo opera através dos que se situam nas alturas, elevando-se e diminuindo os demais. "Trata-se da verticalidade, da desigualdade, da criação de diferenças de valor entre os homens: de tamanho, de nível, de estatura. Trata-se da arrogância, do menosprezo, do poder, da submissão, da dignidade, da humilhação”. Do mesmo modo, se trata “dessa sensação de diminuição dentro de alguém” (LARROSA, 2004, p.266). Trata-se, em suma, do que a nossa sociedade está urdindo diariamente.

Por isso mesmo, se trata de pedagogias culturais que colocam em operação ensinamentos em torno "de quem somos", "de quem deveríamos ser", e "de quem são os 'outros"'. Se as práticas e técnicas para cuidar do corpo e os modos de nomear os que destoam dos corpos-padrões ensinados e valorizados na esfera social não são algo da ordem do "natural", do "desde sempre aí", mas fruto de uma intensa construção discursiva, como espero ter evidenciado, estamos tratando, ao mesmo tempo, de pedagogias culturais ativas e atuantes nessas construções.

Mais especificamente, neste artigo o que ficou mais exposto foram algumas das múltiplas ressonâncias e reverberações de toda uma rede discursiva que posiciona os sujeitos de forma diferencial, construindo padrões corporais e o contrário disso. Parece-me, devido a isso, ser muito necessário investir em pesquisas que tentem conseguir traçar um pouco dos efeitos de pedagogias culturais específicas na concretude da vida cotidiana das pessoas. A meu ver, isso possibilita pensar um pouco sobre as tensões contemporâneas que nos assolam e o quanto há pedagogias culturais em operação nessas mesmas tensões.

\section{Referências}

COSTA, Marisa Vorraber. Velhos temas, novos problemas - a arte de perguntar em tempos pós-modernos. In: COSTA, Marisa Vorraber; BUJES, Maria Isabel Edelweiss (Orgs.). Caminhos investigativos III: riscos e possibilidades de pesquisar nas fronteiras. Rio de Janeiro: DP\&A, 2005. p.199-214.

DAMICO, José Geraldo Soares. "Quantas calorias eu preciso [gastar] para emagrecer com saúde?" Como mulheres jovens aprendem estratégias para cuidar do corpo. Porto Alegre: UFRGS, 2004. 161 f. Dissertação (Mestrado em Educação) - Programa de Pós-Graduação 
em Educação, Faculdade de Educação, Universidade Federal do Rio Grande do Sul, Porto Alegre, 2004.

FOUCAULT, Michel. A hermenêutica do sujeito. São Paulo: Martins Fontes, 2004. GROS, Frédéric. Situação do curso. In: FOUCAULT, Michel. A hermenêutica do sujeito. São Paulo: Martins Fontes, 2004. p.613-661.

LARROSA, Jorge. Tecnologias do eu e educação. In: SILVA, Tomaz Tadeu da (Org.). O sujeito da educação: estudos foucaultianos. Petrópolis, RJ: Vozes, 1994. p.35-86.

LARROSA, Jorge. Educação e diminuição. In: LARROSA, Jorge. Linguagem e Educação depois de Babel. Belo Horizonte: Autêntica, 2004. p.265-294.

LOURO, Guacira Lopes. Corpo, escola e identidade. Educação \& Realidade, Porto Alegre, v.25, n.2, p.59-75, jul/dez 2000.

MOITA LOPES, Luiz Paulo da. Práticas narrativas como espaço de construção das identidades sociais: uma abordagem socioconstrucionista. In: RIBEIRO, Branca Telles; LIMA, Cristina Costa; DANTAS, Maria Tereza Lopes (Orgs.). Narrativa, identidade e clínica. Rio de Janeiro: Edições IPUB/CUCA, 2001. p.55-71.

ORTEGA, Francisco. Da ascese à bio-ascese ou do corpo submetido à submissão ao corpo. In: RAGO, Margareth; ORLANDI, Luiz B. Lacerda; VEIGA-NETO, Alfredo (Orgs.).

Imagens de Foucault e Deleuze: ressonâncias nietzchianas. Rio de Janeiro: DP\&A, 2002. p.139-173.

SCHITTINE, Denise. Blog: comunicação e escrita íntima na internet. Rio de Janeiro: Civilização Brasileira, 2004.

SILVEIRA, Rosa Maria Hessel. Textos e Diferenças. Leitura em REVISTA. Ijuí, n.3 jan//jun 2002.

SKLIAR, Carlos. Pedagogia (improvável) da diferença: e se o outro não estivesse aí?. Rio de Janeiro: DP\&A, 2003. 